Article

\title{
Analysis of Driver's Socioeconomic Characteristics Relating to Speeding Behavior and Crash Involvement: A Case Study in Lahore
}

\author{
Muhammad Ashraf Javid ${ }^{1}$ (D), Nazam Ali ${ }^{2}$ (D), Muhammad Abdullah ${ }^{3}\left(\mathbb{D}\right.$, Tiziana Campisi ${ }^{4, *(\mathbb{D})}$ \\ Syed Arif Hussain Shah ${ }^{5}$ and Suniti Suparp ${ }^{6}$ (D)
}

Citation: Javid, M.A.; Ali, N.; Abdullah, M.; Campisi, T.; Shah, S.A.H.; Suparp, S. Analysis of Driver's Socioeconomic Characteristics Relating to Speeding Behavior and Crash Involvement: A Case Study in Lahore. Infrastructures 2022, 7, 18. https://doi.org/10.3390/ infrastructures7020018

Academic Editors: Mario Lucio Puppio, Fadi Hage Chehade and Flavio Stochino

Received: 23 December 2021

Accepted: 25 January 2022

Published: 27 January 2022

Publisher's Note: MDPI stays neutral with regard to jurisdictional claims in published maps and institutional affiliations.

Copyright: (C) 2022 by the authors. Licensee MDPI, Basel, Switzerland. This article is an open access article distributed under the terms and conditions of the Creative Commons Attribution (CC BY) license (https:// creativecommons.org/licenses/by/ $4.0 /)$.
1 Department of Civil Engineering, NFC Institute of Engineering and Fertilizer Research, Faisalabad 38090, Pakistan; ma.javid@iefr.edu.pk

2 Department of Civil Engineering, School of Engineering, University of Management and Technology, Lahore 54770, Pakistan; nazam.ali@umt.edu.pk

3 Department of Civil Engineering, National University of Computer \& Emerging Sciences, Lahore 54770, Pakistan; abdullah.rana@nu.edu.pk

4 Faculty of Engineering and Architecture, Kore University of Enna, Cittadella Universitaria, 94100 Enna, Italy

5 Department of City and Regional Planning, University of Engineering and Technology, G.T. Road, Lahore 54890, Pakistan; syedarifhussain@uet.edu.pk

6 Department of Civil and Environmental Engineering, Faculty of Engineering, Srinakharinwirot University, Nakhonnayok 26120, Thailand; suniti@g.swu.ac.th

* Correspondence: tiziana.campisi@unikore.it

\begin{abstract}
Speeding is one of the risky behaviors which results in accident involvement causing fatalities and severe injuries. This paper aimed to identify the significant socio-economic characteristics of drivers concerning their speeding behavior and crash involvement. A questionnaire was designed consisting of driver's demographic features, involvement in an accident, penalty on speed violations, and statements on speeding behavior in terms of exceeding the speed limits by $10 \mathrm{~km} / \mathrm{h}$ or more on roads with different speed limits of $60,80,100$, and $120 \mathrm{~km} / \mathrm{h}$ per standard operating speeds on various road types in Pakistan. This survey was conducted in Lahore city and a total of 551 usable samples were obtained. A latent variable of drivers' speeding behavior was introduced; factor loadings were estimated, and an observed variable of drivers' crash experience was defined as the drivers' crash involvement. Ordered regression analysis using the probit function was conducted on speeding behavior and crash involvement. The ordinal analysis revealed that the drivers' age, gender, marital status, employment, vehicle engine size, type of vehicle they drive, and driving frequency per day are good predictors of speeding behavior. Similarly, male drivers' age, vehicle engine size, and type of vehicle they drive were significant predictors of their likelihood to be involved in an accident. The young, single, and male drivers and drivers of cars with an engine capacity above $1.5 \mathrm{~L}$ were more likely to speed and be involved in crashes. These findings provide a clear understanding of a specific group of drivers who have a higher probability of speeding and crash involvement. There is a need to focus on specific demographic factors in the formulation of traffic safety policies and managing speedy drivers' behaviors.
\end{abstract}

Keywords: traffic accident; speeding behavior; probit model; questionnaire survey; Lahore

\section{Introduction}

Road safety is very dependent upon the behaviors and attitude of the drivers' handling motorized vehicles. Most of the Road Traffic Crashes (RTCs) are the result of drivers' inappropriate and risky behavior on roads. In recent times, the frequency and occurrence of the RTCs have become one of the growing and worrisome concerns in Pakistan. RTCs are increasing at an alarming rate in Pakistan and pose serious economic and social challenges in terms of increased fatalities, severe injuries, and loss of public property. The reported 
number of accidents in the year of 2017-2018 was 11,121 [1]. According to the World Health Organization (WHO), there are about 2.4 deaths per 100,000 people in Pakistan [2].The main reasons for these accidents mainly include speeding, dozing off while driving, tiredness, poor vehicle conditions, and lack of driving skills and proper training [3,4]. Speeding and dozing account for more than half of the accidents [4]. Other researchers have also mentioned the main reasonss for road traffic crashes, such as careless driving, ignorant behavior of road users, and irresponsibility of the concerned departments and law-enforcement agencies [5]. The $\mathrm{WHO}$ has reported that the level of speed enforcement in Pakistan is comparatively low as compared with other countries in Asia, which can be a major reason for increased accident fatalities and injuries [6].

Lahore city is also facing the problems of poor traffic safety as many drivers are on roads without a proper driving permit and training [7]. The increased urban population with limited public transport to accommodate demand and increased private vehicle usage has added to the traffic safety issues. Data provided by Rescue 1122 (national emergency service) revealed that there were 350 and 178 deaths due to RTCs in the city during 2018 and 2019, respectively [8]. This decline in RTCs related accident severity can be mainly attributed due to the strict implementation of the use of a helmet for motorcyclists in 2019 as a part of the governments' Accidents Prevention Program (APP) in Lahore city. According to an estimation, around $40 \%$ of the accidents in the city are because of speeding [3,8]. Other reasons for RTCs in Lahore include careless driving and overturning. Most of the previous research studies in Lahore city have focused on various aspects of risky driving behaviors and drivers' likelihood to be involved in an accident based on their attitudes, distractions, and behavioral factors [7,9]. The specific risky behavior of drivers such as speeding behavior needs to be explored, as speeding is a major reason for RTCs.

By looking at the fatalities, injuries, and property losses caused by RTCs in modern society, it is very important to investigate the socio-demographic factors of the drivers which stimulate their speeding behaviors resulting in traffic crashes. There is a need to focus on specific characteristics of speedy drivers to improve traffic safety situations and reduce the number of accidents and related fatalities and injuries. Despite the fact that there are numerous studies conducted by different researchers, there are limited studies on the speeding behavior of drivers which focus on the socio-demographic features of the respondents, especially in the contexts of a developing country like Pakistan. This type of research study would help in formulating traffic regulations, which are expected to create awareness and understanding of the importance of safe driving, for controlling speeding and risking behaviors of specific cohorts of drivers. This paper aimed to determine the significant relationships of drivers' socioeconomic demographics (SEDs) with their likelihood to be involved in speeding behaviors and traffic crashes. The ordered probit model function was used to analyze the collected data. The remainder of this research study is organized in the following manner. Section 2 refers to relevant literature studies. Section 3 describes the employed research and data-collection methods. Section 4 discusses the results and modeling analysis. Based on the findings of the research study, some of the policy implications are described in Section 5. Finally, conclusions are drawn and summarized in Section 6.

\section{Literature Review}

Many factors affect drivers' decision to speed and their likelihood of being involved in an accident such as gender, single social status, extensive driving experience, crash experience, recreational trip purposes [10], car ownership, depression, personal attitudes [11], age, income, profession type, and driving attributes such as experience, engine size, and taxi ownership [12], in addition to social factors [13]. The studies evaluating the effects of gender on speeding behavior overwhelmingly reported that men are more likely to be involved in speeding and subsequent crashes $[14,15]$. They also concluded that men, particularly in the high-income group, tend to speed as compared with others. Furthermore, a study conducted in Sydney, Australia reported similar findings, i.e., men are more likely 
to speed compared with women [16]. In addition to gender, age has been reported to have a significant effect on speeding behavior [17]. For instance, a study conducted in Tabuk city of Saudi Arabia reported that young drivers of less than 30 years of age were involved in more than $60 \%$ of the road crashes [18]. Furthermore, driver experience is also associated with speeding and crash propensity. For example, [15] reported that experienced drivers are more likely to speed as compared with other drivers. A study conducted in Malaysia also reported that drivers with extensive driving experience have higher odds of being involved in speeding [10]. On the contrary, a study targeting young drivers reported that inexperienced drivers with poor driving skills are more likely to be involved in crashes [19]. Drivers without a driving license are more likely to speed and end up in a crash [14]. Time of the day has also been reported to affect speeding behavior [15]. Drivers tend to speed more on weekdays and weekend nights [16]. Old vehicles [14] and trip distance and frequency [12] are also associated with speeding behavior. In addition to the demographic variables, the driver's attitudes, subjective norms, behavioral control, and personality traits are also strong predictors of their speeding behavior and crash propensity [20-27]. Evidence from Queensland, Australia also indicated a strong association between personal attitudes and speeding propensity [11]. Apart from that, there are a number of endogenous and exogenous causes for road crashes which are influenced by specific behaviors of the drivers. It has been reported in the literature that mobile phone use [28], eating habits during driving [29], and the presence of a passenger also influence the driving attitude of the driver [30], contributing to one of the significant causes which leads to road crashes, distraction; additionally, roadside advertisements are found as a potential source of driver distraction and crash propensity [31]. Besides self-reported studies, simulation-based experiments could also be used to identify the factors leading to speeding behaviors and crashes $[32,33]$.

There are significant differences in risk-perceptions of traffic violations among drivers of different characteristics such as gender, household size, driving experience, and income [34]. The age of the driver, poor driving skills, speeding, and frequency of driving are significantly related to traffic violations and accidents [26]. The occupants of light-vehicles at two-way roads tend to encounter more severe injuries than those travelers who are in heavy-vehicles on one-way roads. Women tend to suffer more from serious injuries than men [35]. Traffic violations are strongly related to truck drivers' involvement in a traffic crash, whereas drivers' selfishness, mild social deviance, and safety climate indirectly affect their crash involvement [36]. The driver's greater experience has a positive effect on diminishing driver crash involvement, while traffic violations, change of job, and earlier crash experience have a negative influence and the magnitude of such effects varies across different types of commercial vehicles [37]. The likelihood of being involved in an accident is high for those drivers who are young or old, men, and drivers with speeding violations and recent history of crash experience [38]. Non-usage of a restraint device and speeding intentions are the most significant factors influencing the severity of crashes [39].

As discussed in the above-mentioned studies, numerous socio-economic factors of drivers affect drivers' decision to speed, their perceptions of associated risks with traffic violations, and their likelihood of crash involvement. The influencing nature of significant factors may be different under varying infrastructural, legal, economic, and social constraints. The drivers of different regions possess unique driving and demographic characteristics which greatly affect their risk-taking behavior. Therefore, this study attempted to identify significant demographic and driving aspects of drivers that affect their speeding behavior and crash involvement in Lahore, Pakistan.

\section{Research Methods}

\subsection{Data Collection}

The data were collected with the help of a self-reported questionnaire survey. The designed questionnaire consisted of driver's socio-economic demographics (SEDs), crash experiences, and traffic fines received on speeding and their responses over speeding be- 
haviors. The SEDs included age, gender, marital status, income, profession type, education, driving experience in years, possession of a driving license, vehicle engine size, type of vehicle they drive, and their driving hours per day. All these characteristics were categorized to record their responses properly. The second part of the questionnaire included drivers' responses about their experience of any traffic crash involvement in general and due to over speeding. Drivers were also asked to report their speeding violations and the penalties they have received in the last year. In the third part, drivers were asked to report their speeding behavior on selected roads with different speed limits. The selected roads included $60 \mathrm{~km} / \mathrm{h}, 80 \mathrm{~km} / \mathrm{h}, 100 \mathrm{~km} / \mathrm{h}$, and $120 \mathrm{~km} / \mathrm{h}$ roads as per the standard speed limits of different roads in Pakistan $[6,40]$. The roads with these speed limits were selected to represent a mixture of urban and intercity roads as the focus was to draw a comparison considering their behavioral outcomes. The drivers were expected to report responses considering how often they exceed the speed limits by $10 \mathrm{~km} / \mathrm{h}$ or more on above mentioned four categories of roads. This allowance of $10 \mathrm{~km} / \mathrm{h}$ was selected considering the local practices and relevant literature studies [16,41-43]. The responses were recorded on a five-point Likert scale, i.e., never (1), rarely (2), sometimes (3), very often (4), and always (5). A five-point Likert scale was used seeking the reliability of the data as it offers flexibility to the respondents in making decisions [44].

This survey was conducted at different locations in Lahore city with the help of university students who were trained for this purpose. Purpose-based convenience and random sampling strategies were used in the selection of the drivers. The drivers were briefed regarding the contents of the questionnaire to assure their understating of questionnaire items for extracting exact information, as it helped in obtaining reliable responses. The total usable samples collected were 551. It is pertinent to mention that it was ensured that statements included in the questionnaire were concise and well-understood by the interviewers so that they could explain these statements to the respondents if required. For the sake of extracting exact information, the university students were well informed about the objectives and contents of the questionnaire survey. The survey locations were selected based on assumptions of where it would be easy to interview the drivers. The detailed process and the flow chart of this research study is shown in Figure 1.

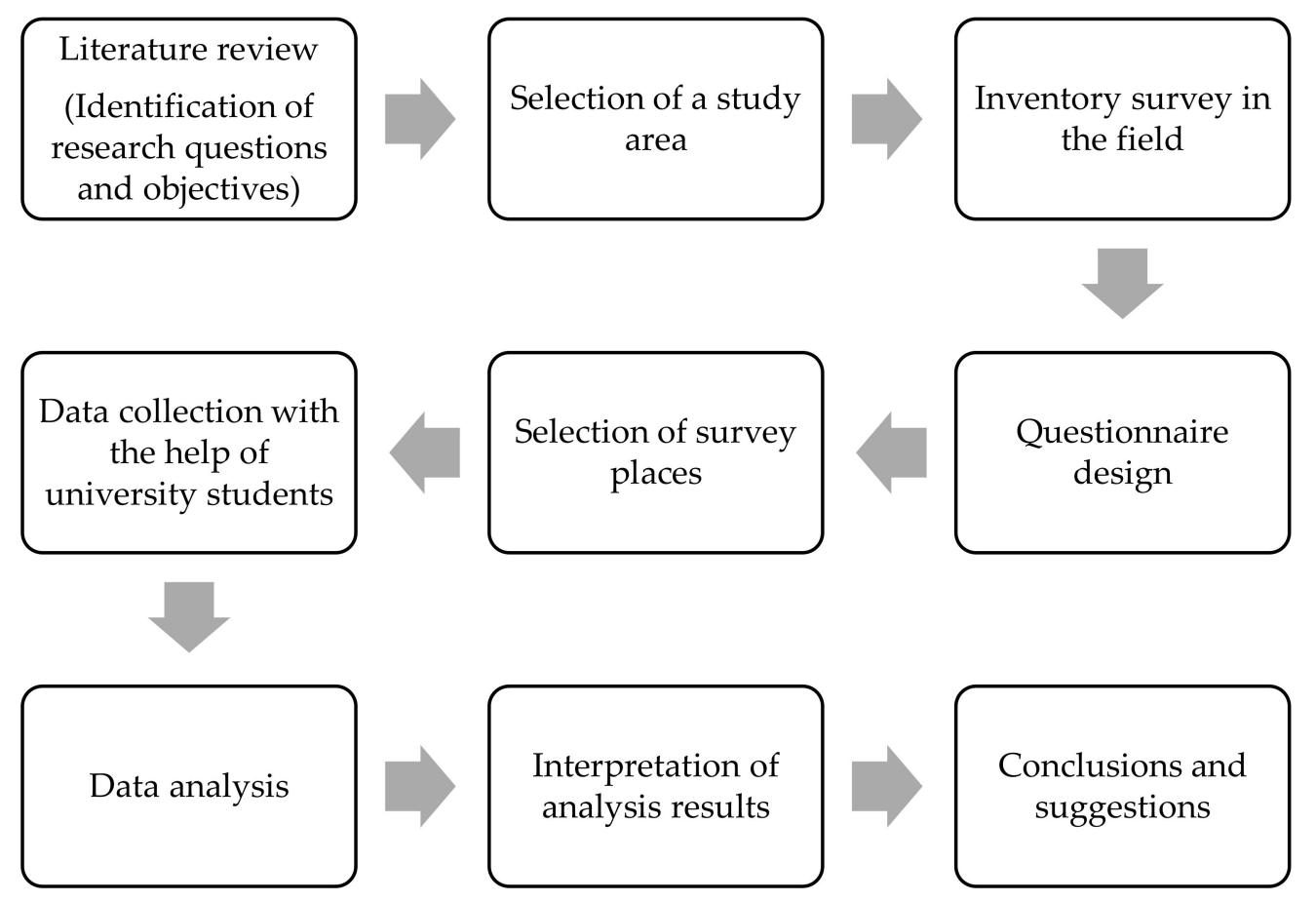

Figure 1. Flow chart of the research study. 


\subsection{Ordered Probit Analysis Specifications}

Ordered regression models help to treat the data consisting of categorical and ranking variables. Ordered Probit models explain the variation of an ordered categorical variable as a function of one or more independent variables. These types of models are used when the dependent variables have around 3 to 7 ordered categories and they belong to the family of Generalized Linear Models (GLMs). GLMs connect the linear combination of independent variables and estimated parameters, which form a link function for the prediction using dependent variable(s). Ordered Probit (OP) analysis was conducted to predict drivers' speeding behavior and crash involvement. The OP model was initially developed by [42]. Ordinal regression analyses are suitable where objective variables have been measured on an ordinal or ranking scale. The variables measured on a dichotomous scale are also acceptable to use in the ordinal regression analysis [45,46]; however, in this case, the analysis became a simple probit regression analysis. The explanatory variables comprising of driver's SEDs were coded as binary variables, i.e., 0 or 1 . It was assumed that the values of the $Y$ variable show the order of the measured items; for example, let ' $Y_{i}{ }^{\prime}$ be the likelihood of involvement in speed violations and a traffic accident of a driver ' $i$ ' as shown in Equations (1)-(3).

$$
\begin{aligned}
& Y_{i}=\left\{\begin{array}{l}
0: \text { never } \\
1: \text { rarely } \\
2: \text { sometimes } \\
3: \text { veryoften } \\
4: \text { always }
\end{array} \Rightarrow\right. \text { speeding behavior } \\
& \begin{array}{r}
0: \text { no } \\
1: \text { yes }
\end{array} \quad \Rightarrow \text { crash experience } \\
& Y_{i}=\beta_{i} X_{i}+\varepsilon
\end{aligned}
$$

where;

$Y_{i}=$ objective variable (latent variable of driver's speeding behavior/observed variable of driver's crash involvement);

$X_{i}=$ a vector of independent or explanatory variables comprising of drivers SEDs; $\beta=$ parameter coefficients of explanatory variables to be estimated; $\varepsilon=$ error term which is assumed to be randomly and normally distributed, and accounts for error in the observed variables and estimation due to external constraints.

The dependent or objective variable of speeding behavior was introduced as a latent variable or factor in an ordered probit model that was extracted from four observed variables on speeding behavior as presented in next Section 4 . This latent variable was extracted using a factor analysis technique. Factor analysis was run using the Maximum Likelihood (ML) method. Cronbach's alpha value was also estimated to check the reliability of the factor. The variable of crash experience or involvement was introduced on a dichotomous variable as an outcome or objective variable. All the explanatory variables of SEDs were coded as binary variables $(0,1)$ to run the ordered probit model.

\section{Results and Analysis}

\subsection{Distribution of Respondent's SEDs}

The distribution of respondents SEDs are shown in Table 1. Most of the respondents were single men. Most of the drivers belonged to the age group of less than 30 years. There was a good distribution of the respondents across three income groups. Students and employees comprised more than $80 \%$ of the sample. More than $75 \%$ of the respondents were drivers of cars, whereas the remaining drove buses, trucks, and wagons, etc. Around $48 \%$ of the drivers had driving experience of more than 4 years. The drivers who drove less than one hour and $1-2 \mathrm{~h}$ per day were $45.4 \%$ and $44.5 \%$, respectively. Results showed that most of the respondents are regular drivers who mainly undertake commuting trips. Almost $46.5 \%$ of the drivers were on roads without a valid driving license, which is consistent with 
other studies [7]. About $48.11 \%$ of the drivers had experienced a traffic accident and $20.30 \%$ of the drivers had received a penalty for a speed violation in the last year. As most the drivers belonged to the young age group, their high involvement in the accidents can be attributed to the fact that they do not possess a driving license. It other words, most of the drivers were young and energetic and did not have proper driving training $(46.50 \%)$; therefore, these can be the leading causes of their involvement in the accidents.

Table 1. Distribution of drivers' SEDs.

\begin{tabular}{|c|c|c|c|}
\hline Characteristics & Category & Frequency & Distribution (\%) \\
\hline \multirow{2}{*}{ Gender } & Man & 457 & 82.94 \\
\hline & Woman & 94 & 17.06 \\
\hline \multirow{2}{*}{ Age (years) } & Less than or equal to 30 & 361 & 65.52 \\
\hline & Above 30 & 190 & 34.48 \\
\hline \multirow{2}{*}{ Marital status } & Single & 409 & 74.22 \\
\hline & Married & 142 & 25.78 \\
\hline \multirow{3}{*}{ Monthly income (PKR) } & Below 30,000 & 208 & 37.70 \\
\hline & $30,000-60,000$ & 138 & 25.00 \\
\hline & Above 60,000 & 205 & 36.30 \\
\hline \multirow{3}{*}{ Profession } & Student & 224 & 40.70 \\
\hline & Employees & 227 & 41.20 \\
\hline & Others & 100 & 18.10 \\
\hline \multirow{3}{*}{ Type of vehicle } & Car & 414 & 75.21 \\
\hline & Bus & 75 & 13.60 \\
\hline & Others & 62 & 11.19 \\
\hline \multirow{4}{*}{ Driving experience } & Less than 1 year & 91 & 16.60 \\
\hline & $1-2$ years & 108 & 19.20 \\
\hline & 3-4 years & 88 & 15.90 \\
\hline & More than 4 years & 264 & 48.30 \\
\hline \multirow{3}{*}{ Driving hours per day } & Less than $1 \mathrm{~h}$ & 250 & 45.40 \\
\hline & $1-2 \mathrm{~h}$ & 245 & 44.50 \\
\hline & More than $2 \mathrm{~h}$ & 56 & 10.20 \\
\hline \multirow{4}{*}{ Vehicle engine capacity } & Under $1 \mathrm{~L}$ & 96 & 17.40 \\
\hline & $1.0-1.5 \mathrm{~L}$ & 192 & 34.80 \\
\hline & $1.6-2.0 \mathrm{~L}$ & 145 & 26.30 \\
\hline & Above $2.0 \mathrm{~L}$ & 118 & 20.70 \\
\hline \multirow{2}{*}{ Driving license } & Yes & 295 & 53.50 \\
\hline & No & 256 & 46.50 \\
\hline \multirow{2}{*}{$\begin{array}{l}\text { Have you ever experienced } \\
\text { an accident? }\end{array}$} & Yes & 265 & 48.11 \\
\hline & No & 286 & 51.89 \\
\hline \multirow{2}{*}{$\begin{array}{l}\text { Have you paid traffic fines due } \\
\text { to speeding in the last one year? }\end{array}$} & Yes & 119 & 20.30 \\
\hline & No & 432 & 79.70 \\
\hline
\end{tabular}

The distribution of the speeding behavior of the drivers with different speed ranges are shown in Figure 2.

The factor loadings and average response of drivers against different speed limits are also shown in Table 2. The results showed that the responses of the drivers were internally consistent as the Cronbach's alpha value was greater than 0.7 [47]. 


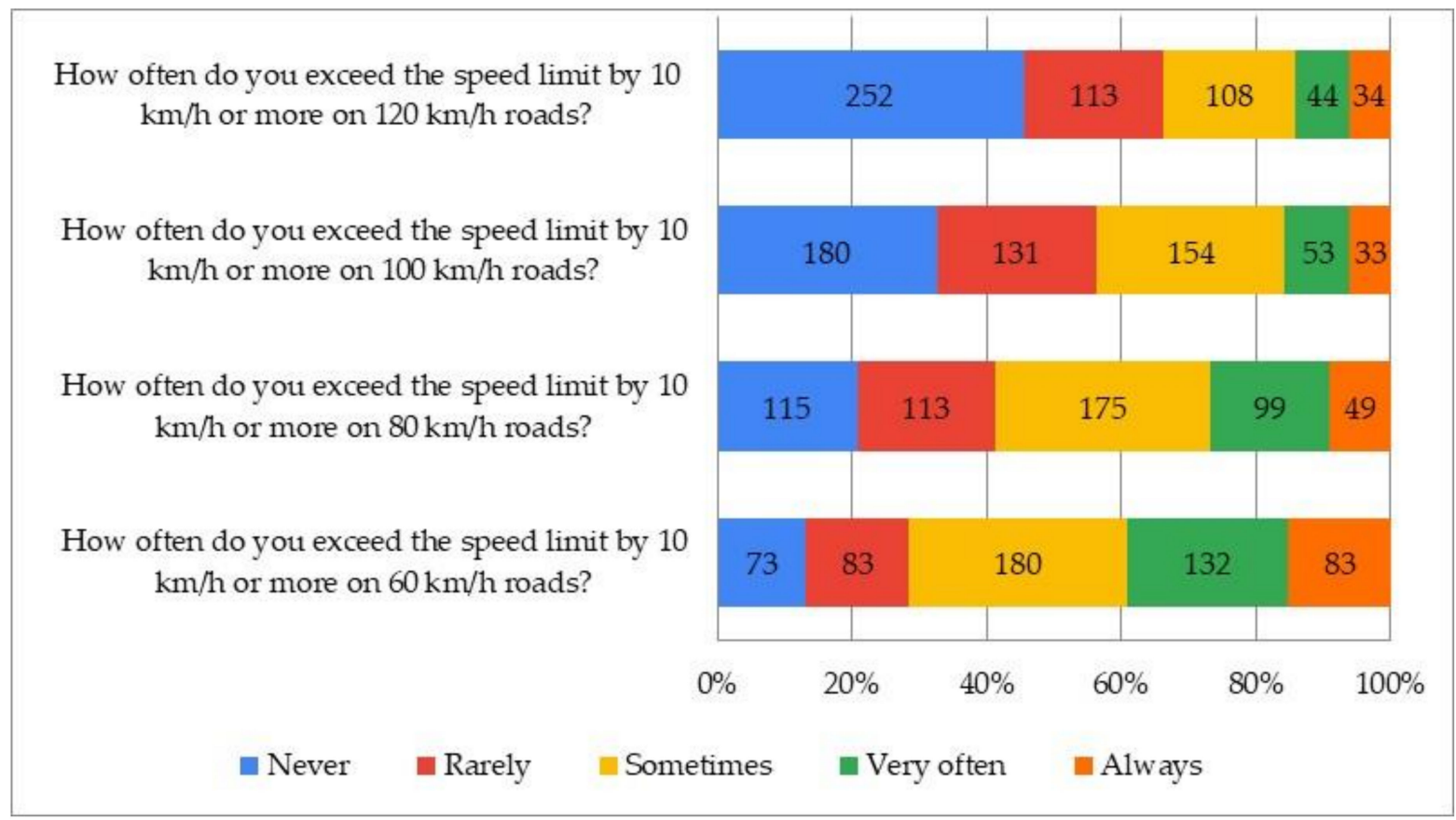

Figure 2. Distribution of responses (\%) on speeding behavior pattern of drivers.

Table 2. Factor loadings and average responses on drivers' speeding behavior.

\begin{tabular}{|c|c|c|c|c|c|}
\hline \multirow{2}{*}{\multicolumn{2}{|c|}{ Observed Variables }} & \multicolumn{4}{|c|}{ Driver's Speeding Behavior } \\
\hline & & \multirow{2}{*}{$\frac{\text { Mean }}{2.350}$} & \multirow{2}{*}{$\begin{array}{c}\text { Factor Loadings } \\
0.932\end{array}$} & \multirow[t]{2}{*}{$\%$ of Variance Explained } & \multirow[t]{2}{*}{ Cronbach's Alpha } \\
\hline How often do you & $100 \mathrm{~km} / \mathrm{h}$ roads? & & & & \\
\hline exceed the speed & $80 \mathrm{~km} / \mathrm{h}$ roads? & 2.750 & 0.829 & \multirow{3}{*}{63.247} & \multirow{3}{*}{0.864} \\
\hline limit by $10 \mathrm{~km} / \mathrm{h}$ & $120 \mathrm{~km} / \mathrm{h}$ roads? & 2.181 & 0.764 & & \\
\hline or more on & $60 \mathrm{~km} / \mathrm{h}$ roads? & 3.115 & 0.624 & & \\
\hline
\end{tabular}

\subsection{Probit Regression Analysis of Speeding Behavior and Crash Involvement}

The OP model analysis was applied to determine significant correlations of driver's SEDs with the latent variable of speeding behavior. Simple probit regression analysis was considered for driver's crash involvement as it has a dichotomous scale. The latent variable of drivers' speeding behavior had the nature of an ordinal variable as its observed variables were evaluated using ordinal scales. The observed variable of drivers' crash involvement had a dichotomous scale as it had only two categories (i.e., yes or no). Many explanatory variables of drivers' SEDs were coded as binary variables (i.e., 0 or 1 ). However, only significant variables are presented below as well as in Table 3.

- $\quad$ Age: 0 if the driver's age is under or equal to 30 years, otherwise is 1.

- Gender: 0 if the driver is a man, otherwise is 1 .

- Marital status: 0 if the driver is single, otherwise is 1.

- Profession: 0 if the driver is an employee, otherwise is 1 .

- Type of vehicle drive: 0 if he or she drives a car, otherwise is 1 .

- Driving frequency: 0 if driving frequency per day is $1-2 \mathrm{~h}$, otherwise is 1 .

- Driving license: 0 if the driver possesses a driving license, otherwise is 1.

- Vehicle engine size variable: 0 if engine size is above $1.5 \mathrm{~L}$, otherwise is 1 .

- Driver's crash involvement: 0 if the driver has experienced an accident, otherwise is 1.

The ordinal probit analysis was performed for both drivers' speeding behavior and crash experience or involvement. The estimation of model parameter values is presented in Table 3. The values of McFadden's pseudo $R^{2}$ of both models were in the range of 
0.2-0.4 [35,46], which showed that probit model estimations are acceptable in predicting speeding behavior and crash involvement. The next subsections discuss the results of each explanatory variable category.

Table 3. Results of the ordered probit model.

\begin{tabular}{ccccc}
\hline \multirow{2}{*}{ Explanatory Variables } & \multicolumn{2}{c}{ Drivers' Speeding Behavior } & Have You Ever Experienced an Accident? (Crash Involvement) \\
\cline { 2 - 5 } & Estimate & $p$-Value & Estimate & $p$-Value \\
\hline Age (under or equal to 30 years) & 0.225 & 0.034 & 0.196 & 0.079 \\
\hline Gender (man) & 0.242 & 0.025 & -0.287 & 0.078 \\
\hline Marital status (single) & 0.214 & 0.056 & 0.443 & 0.001 \\
\hline Employees & -0.263 & 0.080 & 0.061 & 0.601 \\
\hline Car drivers & 0.241 & 0.015 & 0.453 & 0.000 \\
\hline Driving hours (1 to 2 h per day) & 0.235 & 0.008 & -0.021 & 0.854 \\
\hline Driving license & 0.113 & 0.078 & -0.180 & 0.132 \\
\hline Engine size (above 1.5 L) & 0.140 & 0.074 & 0.192 & 0.083 \\
\hline Driver's crash involvement & 0.162 & 0.041 & - & - \\
\hline Likelihood ratio $\left(\rho^{2}\right)$ & 0.231 & 0.000 & 0.225 & 0.000 \\
\hline McFadden's pseudo $R^{2}$ & 0.210 & 0.000 & 0.210 & 0.000 \\
\hline
\end{tabular}

\subsubsection{Age}

The drivers who were up to 30 years of age had a positive coefficient with speeding behavior and crash involvement. Both coefficients were significant at a $5 \%$ level of significance. These positive coefficients predict that the young drivers have more intentions to exceed the speed limits by $10 \mathrm{~km} / \mathrm{h}$ on different kinds of city and intercity roads. Similarly, their likelihood to be involved in an accident is high. The drivers who are older than 30 years have a low propensity to exceed the speed limits and probability to be involved in a crash as the estimated coefficients were negative and significant. Another study also showed that drivers who are under 30 years have more chances to be involved in an accident [18].

\subsubsection{Gender and Marital Status}

Single men have a positive association with speeding behavior. Results showed that drivers who are unmarried men tend to exceed more speed limits by $10 \mathrm{~km} / \mathrm{h}$ than women. The crash involvement propensity of single drivers and those who are men is more as the coefficient was positive and highly significant. However, men have a low likelihood of crash experience as the relationship was negative and significant at a $10 \%$ level of significance. The findings of this study are in agreement with another study [35] which reported that women have a higher propensity to be involved in serious accidents than men.

\subsubsection{Profession}

The drivers who were employees at different public-private organizations had a negative tendency to exceed the speed limits by $10 \mathrm{~km} / \mathrm{h}$ on different kinds of roads. The other professions, such as students, did not show any significant relationship with speeding behavior and crash involvement. Additionally, the coefficient of employees variable with driver crash experience was insignificant.

\subsubsection{Car Drivers}

In the variable of vehicle type, drivers who drove cars were a significant predictor of speeding behavior and crash experience as the coefficients were positive. These positive coefficients showed that car drivers tend to exceed the speed limits more and their likelihood of having an accident is high in comparison with drivers of other vehicles such as buses and trucks. The speeding tendency and crash involvement of different vehicle drivers are usually varied $[35,36]$. 


\subsubsection{Driving Frequency per Day and Possession of a Driving License}

The drivers who had a driving frequency of $1-2 \mathrm{~h}$ per day had a positive association with speeding behavior. This association was highly significant. It means that drivers' driving load is significant in determining their speeding behavior. The drivers who possess a driving license formed a positive correlation with speeding behavior. Usually, the drivers with a driving license feel that they are well trained and feel safe even if they exceed the speed limits, as possession of a driving license has proved to be effective in reducing the crash risks among drivers [48,49]. However, the relationships of driving frequency and possession of driving license variables were insignificant with crash experience.

\subsubsection{Vehicle Engine Size}

The vehicle engine size was a significant predictor of drivers' speeding behavior and crash experience. The drivers who drove a vehicle with engine size up to $1.5 \mathrm{~L}$ had a low propensity to exceed the speed limits, whereas the drivers who drove a vehicle with an engine size more than $1.5 \mathrm{~L}$ had a higher propensity of exceeding the speed limits by $10 \mathrm{~km} / \mathrm{h}$ or more [12,42]. Similarly, the drivers who drove high-engine-size vehicles had a greater likelihood to be involved in an accident [12].

\subsubsection{Crash Experience and Speeding Behavior}

The observed variable of drivers' crash experience or involvement had a positive association with the latent variable of drivers' speeding behavior. It predicts that the drivers who have intentions of exceeding the speed limits by $10 \mathrm{~km} / \mathrm{h}$ or more have more likelihood to be involved in a traffic crash. The drivers' crash and speeding behavior were strongly correlated with each other as reported by [10] as well. This has positive implications in deriving traffic policies and controlling speedy drivers.

\section{Policy Implications}

It was observed that almost half of the drivers on the road (46\%) do not even possess a driving license. A driver without a driving license not only poses a threat to themselves but endangers the lives and properties of the other road users as well, including pedestrians. As most of the respondents (around 65\%) of this study were young drivers of age less than or equal to 30 years, it implies that there is a need for great intervention in young drivers' speeding behaviors. Young drivers have an energetic nature to seek thrill and enjoyment in driving. These results implied that drivers' age is a significant predictor of their speeding intentions and crash involvement. Young drivers need special attention when deriving traffic safety policies concerning speed control and management programs. The government can take some policy measures to look at how these measures can help to intervene in young drivers' speeding behaviors. For making young drivers safe, a coordinated approach is necessary from policymakers, law enforcement agencies [50], media, parents, and young drivers themselves. The success of any proposed policies will only been assured if public and societal acceptance is clearly understood and acted on accordingly [51]. The license-obtaining process itself presents an important opportunity to reduce the risk of unsafe driving of young drivers on roads. It should be noted that safe drivers are made and not born, so the proper training of young drivers should be conducted before issuing them driving licenses [52]. A higher level of accompanied practice and proper training will surely reduce the fatalities on roads. However, it should not be at the expense of making the process itself difficult. To make the driving learning process easy, a dedicated and periodic training program should be launched in various public and private sectors which should target young people to spread awareness about the gravity of the matter [53]. In the formal training programs, a qualified instructor usually provides instructions, but to create technically competent and safe drivers, self-assessment, understanding, and teaching about the factors which contribute to the risks is mandatory. This non-compliance with driving license requirement also raises questions on law enforcement as well, which directly implies that poor management and monitoring of driving behavior is leading to increased 
fatalities on roads. This can be a possible reason that young drivers are more vulnerable to speeding and accidents.

Men and single-status demographics are good predictors of drivers' speeding behavior and crash experience [10]. Single-status drivers usually feel less responsibility, as most of them are young and enthusiastic to drive fast. Such a group of drivers also tend to speed more as their speeding behaviors might have been influenced by racing movies and other speedy drivers [54,55]. An evident reason for more involvement of women in accidents can be attributed to poor training before acquiring a driving license. This can be a result of different social and cultural constraints because not all women are allowed to drive in Pakistan [56].Therefore, there is less probability of attending a training school before acquiring a driving license. Additionally, there are no existent government-run driving training centers where women are appointed to train women drivers. So, many of the privacy, social, and security concerns come into play, which hinder proper training of women [7,57]. It is time that authorities set up and designate proper driving education centers in major cities where proper training can be given to women at reasonable costs, substantially lower than privately owned training centers. It will not only help in making roads safer but would also reduce the dependence of women on men for pick-up and drop-off. Employees or drivers who work at some organizations were found to be safer drivers in comparison with others. This finding adds a new demographic in predicting drivers' speeding behavior and crash involvement. It means that such kinds of drivers show more sense of responsibility on roads while driving.

The results of this study indicated that drivers of light vehicles such as cars, especially with engine sizes of more than $1.5 \mathrm{~L}$, have more propensity to exceed the speed limits, resulting in a higher likelihood of their involvement in a crash. The type of vehicle (light or heavy) significantly affects a driver's decision to speed and crash involvement probability [35]. These drivers need special traffic-enforcement strategies to control their speeding behavior and reduce the risks of being involved in an accident. The driving frequency plays a significant role in drivers' speeding intentions and crash involvement as longer driving hours tend to increase stress and driving anger [26,58]. Sometimes drivers do not exceed the speed limits as they have a fear of being caught and penalized on speed violations [59,60]. So, the speed enforcement and imposition of traffic fines on speeding are essential policies to manage speedy drivers. Whenever a driver violates the traffic rules or speeds, performance scores from their driving license should be deducted. After a specific number of repetitions, the driver should not be allowed to drive for a specified period and should be directed to seek proper training to re-acquire their driving license. Nonetheless, this driving license score system, also known as the license grading system, can only produce substantial benefits if it is coupled with strict compliance and enforcement from traffic police and other traffic-controlling authorities. This will help in controlling speedy drivers and reducing the likelihood of accidents occurring. The reduction in accidents would help in reducing social costs by reducing the severity of injuries, the number of fatalities, and property damages.

\section{Conclusions}

This paper identified the significant socioeconomic demographics of drivers' speeding behavior and crash experience using the results of a questionnaire survey. The ordered probit model was employed to extract significant relationships. The survey results revealed that around half of the drivers did not possess a driving license and have experienced a traffic accident. It was found that the drivers' age, gender (men), marital status (single), employees, car drivers, driving frequency of $1-2 \mathrm{~h}$ per day, possession of a driving license, vehicle engine size, and crash experience are significant attributes of drivers in determining their speeding behavior. The men, single, young, and car drivers have more propensity to exceed the speed limits than other drivers. Similarly, the drivers whose driving frequency is $1-2 \mathrm{~h}$ a day and drive a vehicle with an engine size of more than $1.5 \mathrm{~L}$ have a higher likelihood of speeding. However, the drivers older than 30 years and employees and those 
who drive vehicles with engine size less than $1.5 \mathrm{~L}$ have a low propensity to exceed the speed limits. The drivers who are single and those who are under 30 years old and car drivers who drive a car with an engine size more than $1.5 \mathrm{~L}$ have a higher likelihood to be involved in an accident. Men and those who are older than 30 years old have a lower probability of being involved in a crash.

Considering the significant factors, policy implications were proposed to improve traffic safety through a thorough intervention in the speeding behavior of drivers. Traffic awareness, training programs, and well-defined programs to obtain a driving license are some important policies that need to be integrated with strict traffic enforcement plans of penalizing those who drive without a license to control speedy drivers. Proper implementation and strict monitoring of driving license policy are essential parameters to enhance the traffic safety situation and reduce traffic accidents. The drivers of high-engine-size vehicles need special attention from the law enforcement agencies as they either fall in the category of speedy drivers or potential speedy drivers. The samples of this study were mainly comprised of car drivers and students; therefore, the findings might have limitations in their implications. Future studies should focus on gathering the perception of drivers from two-wheeled vehicles so that a comparison can be drawn in terms of speeding behavior and crash propensity. The perceptions of two-wheeled vehicle drivers may also be included to extract their speeding intentions. Despite limitations, our study can be useful in developing policies to alter the speeding behavior of the young, those without a driving license, and those who drive vehicles with an engine capacity of more than $1.5 \mathrm{~L}$. Additionally, a brief policy about the prevention of women's involvement in a crash is also suggested.

Author Contributions: Conceptualization, M.A.J., N.A., M.A. and T.C.; methodology, M.A. and N.A.; data collection, N.A., M.A.J. and M.A.; data analysis, M.A.J. and N.A.; writing- original draft preparation, M.A.J., N.A., M.A., T.C. and M.A.J.; writing-review and editing, M.A., N.A., S.A.H.S., T.C., M.A.J. and S.S.; funding, T.C. All authors have read and agreed to the published version of the manuscript.

Funding: This research received no external funding.

Institutional Review Board Statement: Ethical review and approval were waived for this study, due to this study being a non-interventional study and did not involve biological human experiments and patient data. In addition, this study was completely voluntary and non-coercive, and responses remain anonymous.

Informed Consent Statement: Not applicable.

Data Availability Statement: The data can be availed from corresponding author upon reasonable request.

Conflicts of Interest: The authors declare no conflict of interest.

\section{References}

1. Pakistan Bureau of Statistics. Data on Traffic Accidents; Pakistan Bureau of Statistics: Islamabad, Pakistan, 2019.

2. World Health Organization. Road Traffic Injuries. Available online: https://www.who.int/news-room/fact-sheets/detail/roadtraffic-injuries (accessed on 8 July 2020).

3. Tahir, N.; Naseer, R.; Khan, S.M.; Macassa, G.; Hashmi, W.; Durrani, M. Road traffic crashes managed by Rescue 1122 in Lahore, Pakistan. Int. J. Inj. Control Saf. Promot. 2012, 19, 347-350. [CrossRef] [PubMed]

4. Rizwan, S.; Ejaz, H.; Iqbal, F.; Iqbal, S.; Khan, I.A. Severity and Causes of Accidents on Motorway M-1 and M-2. Pak. Armed Forces Med. J. 2018, 68, 1023-1027.

5. Nadeem, M.S.; Hussain, Z.; Muddassar, M.; Nadeem, M.K. Socio-Causative Trends of Road Traffic Accidents in Pakistan Socio-Causative Trends of Road Traffic Accidents in Pakistan. Sci. Int. 2015, 27, 3837-3842.

6. World Health Organization. Global Status Report on Road Safety; WHO: Geneva, Switzerland, 2018.

7. Javid, M.A.; Faraz, N.S. Understanding the Behaviour of Young Drivers in Relation To Traffic Safety. Pak. J. Sci. 2017, 69, 144-149.

8. The Express Tribune. In Lahore, Road Accident Casualties Decline in 2019. Available online: https://tribune.com.pk/story/2102 182/lahoreroad-accident-casualties-decline-2019 (accessed on 3 August 2020).

9. Batool, Z.; Carsten, O. Attitudinal determinants of aberrant driving behaviors in Pakistan. Transp. Res. Rec. 2016, 2602, 52-59. [CrossRef] 
10. Mohamad, F.F.; Abdullah, A.S.; Mohamad, J. Are sociodemographic characteristics and attitude good predictors of speeding behavior among drivers on Malaysia federal roads? Traffic Inj. Prev. 2019, 20, 478-483. [CrossRef]

11. Scott-Parker, B.; Hyde, M.K.; Watson, B.; King, M.J. Speeding by young novice drivers: What can personal characteristics and psychosocial theory add to our understanding? Accid. Anal. Prev. 2013, 50, 242-250. [CrossRef]

12. Hossain, Q.S.; KABIR, M.E.; Hossain, M.K.; Liza, R.; Wan Hashim, W.I.; Leong, L.V. Characteristics and Crash Involvement of Speeding, Violating and Thrill-Seeking Baby-Taxi Drivers in Khulna Metropolitan City, Bangladesh. Proc. East. Asia Soc. Transp. Stud. 2005, 5, 1900-1908.

13. Bates, L.J.; Davey, J.; Watson, B.; King, M.J.; Armstrong, K. Factors contributing to crashes among young drivers. Sultan Qaboos Univ. Med. J. 2014, 14, e297.

14. Høye, A. Speeding and impaired driving in fatal crashes-Results from in-depth investigations. Traffic Inj. Prev. 2020, 21, 425-430. [CrossRef]

15. Kang, K. Socioeconomic Characteristics of Speeding Behavior. In Proceedings of the First International Driving Symposium on Human Factors in Driver Assessment, Training and Vehicle Design, Aspen, CO, USA, 14-17 August 2001; pp. 320-324.

16. Ellison, A.B.; Greaves, S. Driver characteristics and speeding behaviour. In Proceedings of the ATRF 2010: 33rd Australasian Transport Research Forum, Canberra, Australia, 29 September-1 October 2010; pp. 1-17.

17. Čulík, K.; Kalašová, A. Statistical Evaluation of BIS-11 and DAQ Tools in the Field of Traffic Psychology. Mathematics 2021, 9, 433. [CrossRef]

18. Issa, Y. Effect of driver's personal characteristics on traffic accidents in Tabuk city in Saudi Arabia. J. Transp. Lit. 2016, 10, 25-29. [CrossRef]

19. Rolison, J.J.; Regev, S.; Moutari, S.; Feeney, A. What are the factors that contribute to road accidents? An assessment of law enforcement views, ordinary drivers' opinions, and road accident records. Accid. Anal. Prev. 2018, 115, 11-24. [CrossRef] [PubMed]

20. Åkerstedt, T.; Kecklund, G. Age, gender and early morning highway accidents. J. Sleep Res. 2001, 10, 105-110. [CrossRef] [PubMed]

21. Regev, S.; Rolison, J.J.; Moutari, S. Crash risk by driver age, gender, and time of day using a new exposure methodology. J. Saf. Res. 2018, 66, 131-140. [CrossRef]

22. Lucidi, F.; Girelli, L.; Chirico, A.; Alivernini, F.; Cozzolino, M.; Violani, C.; Mallia, L. Personality Traits and Attitudes Toward Traffic Safety Predict Risky Behavior Across Young, Adult, and Older Drivers. Front. Psychol. 2019, 10, 536. [CrossRef]

23. Kong, J.; Zhang, K.; Chen, X. Personality and attitudes as predictors of risky driving behavior: Evidence from Beijing drivers. In Proceedings of the Lecture Notes in Computer Science; Springer: Berlin/Heidelberg, Germany, 2013; Volume 8025 LNCS, pp. 38-44.

24. Javid, M.A.; Al-Roushdi, A.F.A. Causal Factors of Driver's Speeding Behaviour, a Case Study in Oman: Role of Norms, Personality, and Exposure Aspects. Int. J. Civ. Eng. 2019, 17, 1409-1419. [CrossRef]

25. Mallia, L.; Lazuras, L.; Violani, C.; Lucidi, F. Crash risk and aberrant driving behaviors among bus drivers: The role of personality and attitudes towards traffic safety. Accid. Anal. Prev. 2015, 79, 145-151. [CrossRef]

26. Shi, J.; Xiao, Y.; Tao, L.; Atchley, P. Factors causing aberrant driving behaviors: A model of problem drivers in China. J. Transp. Saf. Secur. 2018, 10, 288-302. [CrossRef]

27. Javid, M.A.; Ali, N.; Abdullah, M.; Shah, S.A.H. Integrating the Norm Activation Model (NAM) Theory in Explaining Factors Affecting Drivers' Speeding Behaviour in Lahore. KSCE J. Civ. Eng. 2021, 25, 2701-2712. [CrossRef]

28. Choudhary, P.; Velaga, N.R. Mobile phone use during driving: Effects on speed and effectiveness of driver compensatory behaviour. Accid. Anal. Prev. 2017, 106, 370-378. [CrossRef] [PubMed]

29. Choudhary, P.; Velaga, N.R. A comparative analysis of risk associated with eating, drinking and texting during driving at unsignalised intersections. Transp. Res. Part F Traffic Psychol. Behav. 2019, 63, 295-308. [CrossRef]

30. Caird, J.K.; Simmons, S.M.; Wiley, K.; Johnston, K.A.; Horrey, W.J. Does Talking on a Cell Phone, With a Passenger, or Dialing Affect Driving Performance? An Updated Systematic Review and Meta-Analysis of Experimental Studies. Hum. Factors 2018, 60, 101-133. [CrossRef] [PubMed]

31. Oviedo-Trespalacios, O.; Truelove, V.; Watson, B.; Hinton, J.A. The impact of road advertising signs on driver behaviour and implications for road safety: A critical systematic review. Transp. Res. Part A Policy Pract. 2019, 122, 85-98. [CrossRef]

32. Čulík, K.; Kalašová, A.; Kubíková, S. Simulation as an Instrument for Research of Driver-vehicle Interaction. MATEC Web Conf. 2017, 134, 00008. [CrossRef]

33. Čulík, K.; Harantová, V.; Hájnik, A. CAD Software Using for Designing of Traffic Environment. Transp. Res. Proc. 2020, 44, 248-254. [CrossRef]

34. Machado-León, J.L.; De Oña, J.; De Oña, R.; Eboli, L.; Mazzulla, G. Socio-economic and driving experience factors affecting drivers' perceptions of traffic crash risk. Transp. Res. Part F Traffic Psychol. Behav. 2016, 37, 41-51. [CrossRef]

35. Garrido, R.; Bastos, A.; De Almeida, A.; Elvas, J.P. Prediction of road accident severity using the ordered probit model. Transp. Res. Proc. 2014, 3, 214-223. [CrossRef]

36. Sullman, M.J.M. Factors Affecting the Risk of Crash Involvement Amongst New Zealand Truck Drivers. Ph.D. Thesis, Massey University, Palmerston North, New Zealand, 2002.

37. Lee, J.; Yeo, J.; Yun, I.; Kang, S.; Zeng, Q. Factors Affecting Crash Involvement of Commercial Vehicle Drivers: Evaluation of Commercial Vehicle Drivers' Characteristics in South Korea. J. Adv. Transp. 2020, 2020, 5868379. [CrossRef] 
38. Chandraratna, S.; Stamatiadis, N.; Stromberg, A. Crash involvement of drivers with multiple crashes. Accid. Anal. Prev. 2006, 38, 532-541. [CrossRef]

39. Dissanayake, S. Comparison of Severity Affecting Factors between Young and Older Drivers Involved In Single Vehicle Crashes. IATSS Res. 2004, 28, 48-54. [CrossRef]

40. Ministry of Communications Pakistan. National Road Safety Strategy 2018-2030-A Strategy to Save More than 6,000 Lives by 2030; Ministry of Communications Pakistan: Islamabad, Pakistan, 2018.

41. Warner, H.W.; Åberg, L. Drivers' decision to speed: A study inspired by the theory of planned behavior. Transp. Res. Part F Traffic Psychol. Behav. 2006, 9, 427-433. [CrossRef]

42. Javid, M.A.; Al-Hashimi, A.R. Significance of attitudes, passion and cultural factors in driver's speeding behavior in Oman: Application of theory of planned behavior. Int. J. Inj. Control Saf. Promot. 2020, 27, 172-180. [CrossRef] [PubMed]

43. Mehmood, A. Determinants of speeding behavior of drivers in Al Ain (United Arab Emirates). J. Transp. Eng. 2009, 135, 721-729. [CrossRef]

44. Vagias, W.M. Likert-Type Scale Response Anchors; Clemson International Institute for Tourism \& Research Development, Department of Parks, Recreation and Tourism Management: Clemson, SC, USA, 2011.

45. McKelvey, R.D.; Zavoina, W. A statistical model for the analysis of ordinal level dependent variables. J. Math. Sociol. 1975, 4, 103-120. [CrossRef]

46. Winship, C.; Mare, R.D. Regression Models with Ordinal Variables. Am. Sociol. Rev. 1984, 49, 512. [CrossRef]

47. Taber, K.S. The Use of Cronbach's Alpha When Developing and Reporting Research Instruments in Science Education. Res. Sci. Educ. 2018, 48, 1273-1296. [CrossRef]

48. Fell, J.C.; Jones, K.; Romano, E.; Voas, R. An evaluation of graduated driver licensing effects on fatal crash involvements of young drivers in the United States. Traffic Inj. Prev. 2011, 12, 423-431. [CrossRef]

49. Sagberg, F. Characteristics of fatal road crashes involving unlicensed drivers or riders: Implications for countermeasures. Accid. Anal. Prev. 2018, 117, 270-275. [CrossRef]

50. Yang, B.M.; Kim, J. Road traffic accidents and policy interventions in Korea. Inj. Control Saf. Promot. 2003, 10, 89-94. [CrossRef]

51. Dinh, D.D.; Kubota, H. Speeding behavior on urban residential streets with a $30 \mathrm{~km} / \mathrm{h}$ speed limit under the framework of the theory of planned behavior. Transp. Policy 2013, 29, 199-208. [CrossRef]

52. Hussain, M.; Shi, J. Effects of proper driving training and driving license on aberrant driving behaviors of Pakistani drivers-A Proportional Odds approach. J. Transp. Saf. Secur. 2019, 13, 661-679. [CrossRef]

53. Suriyawongpaisal, P.; Kanchanasut, S. Road Traffic Injuries in Thailand: Trends, Selected Underlying Determinants and Status of Intervention. Inj. Control Saf. Promot. 2003, 10, 95-104. [CrossRef] [PubMed]

54. Kunnawee, K.; Ketphat, M.; Jiwattanakulpaisarn, P. Application of the theory of planned behaviour to predict young drivers' speeding behaviour. Inj. Prev. 2012, 18, A1-A246. [CrossRef]

55. Iversen, H. Risk-taking attitudes and risky driving behaviour. Transp. Res. Part F Traffic Psychol. Behav. 2004, 7, 135-150. [CrossRef]

56. Javid, M.A.; Okamura, T.; Nakamura, F.; Tanaka, S.; Wang, R. People's behavioral intentions towards public transport in Lahore: Role of situational constraints, mobility restrictions and incentives. KSCE J. Civ. Eng. 2016, 20, 401-410. [CrossRef]

57. Batool, Z.; Carsten, O.; Jopson, A. Road safety issues in Pakistan: A case study of Lahore. Transp. Plan. Technol. 2012, 35, 31-48. [CrossRef]

58. Montoro, L.; Useche, S.; Alonso, F.; Cendales, B. Work environment, stress, and driving anger: A structural equation model for predicting traffic sanctions of public transport drivers. Int. J. Environ. Res. Public Health 2018, 15, 497. [CrossRef]

59. Alonso, F.; Esteban, C.; Calatayud, C.; Sanmartín, J. Speed and Road Accidents: Behaviors, Motives, and Assessment of the Effectiveness of Penalties for Speeding. Am. J. Appl. Psychol. 2013, 1, 58-64. [CrossRef]

60. Lawpoolsri, S.; Li, J.; Braver, E.R. Do speeding tickets reduce the likelihood of receiving subsequent speeding tickets? A longitudinal study of speeding violators in Maryland. Traffic Inj. Prev. 2007, 8, 26-34. [CrossRef] 